Research Paper

\title{
Bioremediation of dyes by fungi isolated from contaminated dye effluent sites for bio-usability
}

\author{
Babita Rani ${ }^{1}$, Vivek Kumar ${ }^{2}$, Jagvijay Singh ${ }^{3}$, Sandeep Bisht ${ }^{4}$, Priyanku Teotia ${ }^{5}$, \\ Shivesh Sharma ${ }^{6}$, Ritu Kela ${ }^{1}$ \\ ${ }^{1}$ Department of Biochemistry, Division of Biosciences, College of Applied Education \& Health Sciences, \\ Meerut, India. \\ ${ }^{2}$ Amity Institute of Microbial Technology, AMITY University, Noida, India. \\ ${ }^{3}$ Department of Biotechnology, Division of Biosciences, \\ College of Applied Education \& Health Sciences, Meerut, India. \\ ${ }^{4}$ Department of Microbiology, Uttrakhand University of Horticulture \& Forestry, Bharsar, India. \\ ${ }^{5}$ Department of Botany, Meerut College, Meerut, India. \\ ${ }^{6}$ Department of Biotechnology, MLN National Institute of Technology, Allahabad, India.
}

Submitted: August 20, 2013; Approved: March 14, 2014.

\begin{abstract}
Biodegradation and detoxification of dyes, Malachite green, Nigrosin and Basic fuchsin have been carried out using two fungal isolates Aspergillus niger, and Phanerochaete chrysosporium, isolated from dye effluent soil. Three methods were selected for biodegradation, viz. agar overlay and liquid media methods; stationary and shaking conditions at $25{ }^{\circ} \mathrm{C}$. Aspergillus niger recorded maximum decolorization of the dye Basic fuchsin (81.85\%) followed by Nigrosin $(77.47 \%)$, Malachite green (72.77\%) and dye mixture (33.08\%) under shaking condition. Whereas, P. chrysosporium recorded decolorization to the maximum with the Nigrosin $(90.15 \%)$ followed by Basic fuchsin (89.8\%), Malachite green $(83.25 \%)$ and mixture $(78.4 \%)$. The selected fungal strains performed better under shaking conditions compared to stationary method; moreover the inoculation of fungus also brought the $\mathrm{pH}$ of the dye solutions to neutral from acidic. Seed germination bioassay study exhibited that when inoculated dye solutions were used, seed showed germination while uninoculated dyes inhibited germination even after four days of observation. Similarly, microbial growth was also inhibited by uninoculated dyes. The excellent performance of $A$. niger and $P$. chrysporium in the biodegradation of textile dyes of different chemical structures suggests and reinforces the potential of these fungi for environmental decontamination.
\end{abstract}

Key words: bioremediation, dyes, fungi, microbial bioassay, seed germination.

\section{Introduction}

Due to rapid industrialization and urbanization, a lot of chemicals including dyes are manufactured and are being used in day-to-day life. About 100,000 commercial dyes are manufactured including several varieties of dyes such as acidic, basic, reactive, azo, diazo, anthraquinone based meta complex dyes with an annual production of over $7 \times 10^{5}$ metric tons are commercially available (Campos et al., 2001). Approximately $50 \%$ of the dyes are released in the industrial effluents (Zollinger, 1991). They are used on several substrates in food, cosmetics, paper, plastic and textile industries. Some of them are dangerous to living organisms due to their potential toxicity and carcinogenicity. Dyes in wastewater often lead to calamities viz. the incidence of bladder tumors has been reported to be particularly higher in dye industry workers than in the general population (Suryavathi et al., 2005). Natural pigments used for coloring textiles have been replaced by "fast colors" which do not fade on exposure to light, heat and water. These features unfortunately go with the perils of harmful 
effluent quality. About $15 \%$ of the dyes used for textile dying are released into processing waters (Eichlerova et al., 2006). Besides being unaesthetic, these effluents are mutagenic, carcinogenic and toxic (Chung et al., 1992).

Commonly applied treatment methods for color removal from colored effluents consist of integrated processes involving various combinations of biological, physical and chemical decolorization methods (Galindo and Kalt, 1999; Robinson et al., 2001; Azbar et al., 2004), of these, approximately $10-15 \%$ of unused dyes enter the wastewater after dyeing and after the subsequent washing processes (Rajamohan and Karthikeyan, 2006). Chemical and physical methods for treatment of dye wastewater are not widely applied to textile industries because of exorbitant costs and disposal problems. Green technologies to deal with this problem include adsorption of dyestuffs on bacterial and fungal biomass (Fu and Viraraghavan, 2002; Yang et al., 2009) or low-cost non-conventional adsorbents (Crini 2006; Ferrero, 2007).

A variety of physicochemical treatments have been devised previously for the dyes and textile wastewater. However, these suffered from some serious drawbacks in terms of their limited applications or their high cost. Besides, chemical treatments created an additional chemical load in water bodies that eventually resulted in sludge disposal problems. Several factors determine the technical and economic feasibility of each single dye removal technique. These include; dye type and its concentration, wastewater composition, operation costs (energy and material), environmental fate and handling costs of generated waste products. A very small amount of dye in water $(10-50 \mathrm{mg} / \mathrm{L})$ is highly visible and reduces light penetration in water systems, thus causing a negative effect on photosynthesis (Khaled et al., 2010; Dhanjal et al., 2013).

Recently, dye removal became a research area of increasing interest, as government legislation concerning the release of contaminated effluent becomes more stringent. Various treatment methods for removal of dyes from industrial effluents like chemical coagulation using alum, lime, ferric chloride, ferric sulphate and electro coagulation are very time consuming and costly with low efficiency. Among the numerous water treatment technologies, research interest in the fungal bioremediation due to their biomass compared to the bacteria, has increased significantly for decolorization and degradation of synthetic dyes (Shahid et al., 2013).

Many authors have already worked with many microorganisms, the imperative bacteria being Staphylococcus arlettae (Elisangela et al., 2009); Lactic acid bacteria (Khaled et al., 2010); Pseudomonas putida (Leebana et al., 2012); Micrococcus luteus, Listeria denitrificans and Nocardia atlantica (Hassan et al., 2013) Bacillus megaterium (Joshi et al., 2013), and fungi viz. Basidiomycetous fungi (Machado et al., 2006); Tramates pubescens and Pleurotus ostreatus (Casieri et al., 2008);
Aspergillus tamarii and Penicillium purpurogenum (Ramalingam et al., 2010); Aspergillus ochraceus (Tisma et al., 2012); and Pleurotus ostreatus (Siddique et al., 2012); Aspergillus niger, Fusarium oxysporum and Trichoderma lignorum (Shahid et al., 2013).

Keeping the above points in view, the main objectives of the problem were to screen and employ selected potential textile dye effluent soil fungal sp. capable to decolorize and detoxify the textile dyes using solid and liquid media under shaking and stationary conditions.

\section{Methods and Materials}

\section{Chemicals and media}

All the chemicals, dyes and media such as Potato Dextrose Agar (PDA), Potato Dextrose broth (PDB) and Nutrient agar (NA) were procured from Himedia, Mumbai, India.

\section{Dyes used}

Malachite green (4-[(4-dimethylaminophenyl) phenyl-methyl]-N, N-dimethylaniline) Molecular formula: $\mathrm{C}_{23} \mathrm{H}_{25} \mathrm{C}_{1} \mathrm{~N}_{2}$,

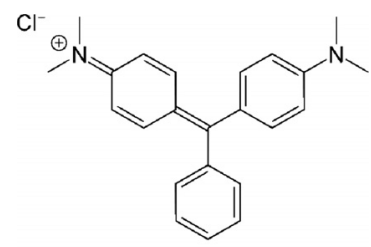

Malachite green

Nigrosin disodium; 4-amino-3-[(4-nitrophenyl) diazenyl] - 5-oxo-6- (phenylhydrazinylidene) naphthalene-2, 7-disulfonate, Molecular formula: $\left(\mathrm{C}_{22} \mathrm{H}_{14} \mathrm{~N}_{6} \mathrm{Na}_{2} \mathrm{O}_{9} \mathrm{~S}_{2}\right)$,

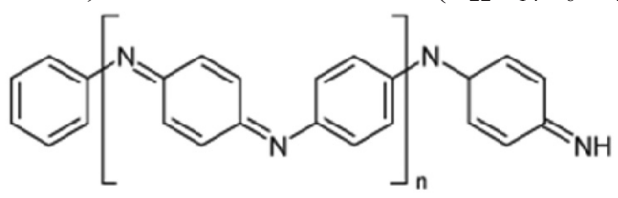

Nigrosin

Basic fuchsin (4-[(4-Aminophenyl)-(4-imino-1-cyclohexa-2,5-dienylidene) methyl] aniline hydrochloride): Molecular formula: $\mathrm{C}_{20} \mathrm{H}_{20} \mathrm{~N}_{3} \mathrm{HCl}$ ) and mixture of all dyes.<smiles>Cc1cc(C(=C2C=CC(=N)C=C2)c2ccc(N)cc2)ccc1N</smiles>

Basic Fuchsin 


\section{Source of fungal strains}

The dye effluent soil-isolated (from Meerut region, Uttar Pradesh, India) fungal strains A. niger and $P$. chrysosporium were maintained on Potato Dextrose Agar (Himedia, Mumbai, India) and sub cultured periodically to maintain their viability. Identification of these soil fungal strains was done previously based on their morphological characters (Yao et al., 2009). These fungi have selected in present study because $A$. niger and $P$. chrysosporium has been widely studied for dye decolorization.

\section{Screening of soil-derived fungi for dye decolorization activities}

Sixty one dye effluent soil fungal strains were screened for their ability to degrade dyes using the tube overlay method. Initially, the fungal strains were grown on culture plates pre-filled with Potato Dextrose Agar (PDA) and incubated at room temperature for 14 days. Following incubation, mycelial agar plugs $\left(\sim 5 \mathrm{~mm}^{2}\right)$ were cut approximately $5 \mathrm{~mm}$ from the colony margin and inoculated on test tubes (in triplicates) containing $5 \mathrm{~mL}$ of PDA overlaid with $1 \mathrm{~mL}$ of PDA with $0.01 \%(\mathrm{w} / \mathrm{v})$ respective textile dye. All culture tubes were incubated at room temperature $\left(\sim 25^{\circ} \mathrm{C}\right)$ and observed weekly for up to four weeks. Clearing of the overlaid dye indicates full decolorization $(+++)$. Partial dye decolorization $(++)$ was indicated by less dye intensity in comparison with the control (uninoculated PDA overlaid with PDA $+0.01 \%$ dye). All the three fungal strains were selected on the basis of full or maximum $(+++)$ decolorization.

\section{Decolorization of dyes in solid medium (Tube overlay method)}

The two selected fungal strains were further tested for their ability to decolorize on PDA and Sabouraud Dextrose Agar (SDA) medium, Himedia, Mumbai, India. This was done to select which medium support better growth and dye decolorization activities of selected fungal isolates. Initially, all the three fungal strains were grown as previously described. Following incubation, fungal mycelial agar plugs $\left(\sim 5 \mathrm{~mm}^{2}\right)$ were cut approximately $5 \mathrm{~mm}$ from the colony margin and inoculated on test tubes (in triplicates) each pre-filled with $2 \mathrm{~mL}$ of the Potato Dextrose Agar (PDA) and SDA medium, supplemented separately with either with following dye $0.01 \%(\mathrm{w} / \mathrm{v})$ Malachite green, Nigrosin and Basic fuchsin, respectively (Lopez et al., 2006). The culture tubes were then incubated at room temperature $\left(\sim 25^{\circ} \mathrm{C}\right)$. The growth of the fungi and its ability to decolorize the dye were observed weekly up to four weeks. The depth of dye decolorization (in $\mathrm{mm}$ ) indicated by clearing of the dye was then measured. Based upon growth of fungal strains and dye decolorization, for further studies PDA medium was chosen.

\section{Assay for the dye decolorization activities of fungi in liquid media}

The spores and mycelia of A. niger and $P$. chrysosporium were then dislodged from Petri plates using a flame-sterilized inoculating loop and mixed properly with one $\mathrm{mL}$ of sterile distilled water. From this mixture, $10 \mu \mathrm{L}$ of the fungal spore and mycelium inoculum were added on culture vials (in triplicates) pre-filled with $25 \mathrm{~mL}$ Potato Dextrose Broth (PDB) supplemented with $0.01 \%$ of either one of the following dyes: Malachite green, Nigrosin and Basic fuchsin. Three sets were prepared and were incubated either under constant agitation/shaking (100 rpm, Yorko Scientific Orbital Shaker) or under stationary/without shaking condition (Park et al., 2007). All culture vials were incubated at room temperature $\left(\sim 25^{\circ} \mathrm{C}\right)$ for 10 days and all assays were performed in triplicate. Growth and dye decolorization were noted every day. Following culture for 10 days, the culture filtrates were decanted and subjected to spectrophotometric analysis. Absorbance maxima of the tested dyes were read as malachite green-620 nm, Nigrosin-600 nm and Basic fuchsin-550 nm wavelength. The extent of dye decolorization by the soil fungal strains on liquid media was calculated using the formula below:

$$
\text { Pdd }(\%)=\frac{\text { Absorbance }_{\mathrm{c}}-\text { Absorbance }_{\mathrm{i}}}{\text { Absorbance }_{\mathrm{c}}} \times 100
$$

where Pdd $=$ Percent dye decolorization, Absorbance $_{\mathrm{c}}=$ Absorbance control and Absorbance $\mathrm{i}_{\mathrm{i}}=$ Absorbance inoculated.

Finally, the mycelial biomass were harvested on clean Petri plates and observed directly. Fungal hyphae were also mounted on clean glass slides and observed under a compound light microscope, make Olympus (1500x) for the biosorption of dyes.

\section{Enzyme assay}

Laccase activity was measured by using syringaldazine as a substrate as per the method of (Valmaseda et al., 1991). The activity was assayed using using $1.0 \mathrm{~mL}$ of $0.2 \mathrm{M}$ sodium phosphate buffer $(\mathrm{pH} 5.7)$ and $0.2 \mathrm{~mL}$ syringaldazine $(1.6 \mathrm{mg} / \mathrm{mL})$ in absolute ethanol, $(4.47 \mathrm{Mm})$. Reactions were initiated by the addition of syringaldazine and after mixing; incubations were conducted at $30^{\circ} \mathrm{C}$ for $1 \mathrm{~h}$, because after $1 \mathrm{~h}$ highest enzyme laccase activity was observed. The absorbance was measured in a spectrophotometer (ELICO SL 150) before (0 time) and after incubation (60 min) at $526 \mathrm{~nm}$ and the increase in absorbance was calculated. One unit activity was defined as the enzyme producing one absorption unit/min at $526 \mathrm{~nm}$.

\section{Seed germination bioassay}

Effect of bioremediated and untreated dye solution was observed on wheat seed germination. The wheat seeds were sterilized using $0.1 \% \mathrm{HgCl}_{2}$ solution for $50 \mathrm{~s}$, washed 
6-7 times with sterile distilled water to remove traces of $\mathrm{HgCl}_{2}$. In sterile Petri plates sterile filter paper was kept soaked in bioremediated, untreated dye solution and with sterile distilled water soaked filter paper as control, respectively. Ten wheat seeds were kept in each Petri plate and the experiment was conducted in triplicate. Observation on seed germination was taken for four days. The experiment was conducted at room temperature of $25 \pm 1{ }^{\circ} \mathrm{C}$.

\section{Bacterial toxicity}

Effect of bioremediated and untreated dye solution was observed on bacterial growth by measuring zone of inhibition. Log phase cells of E. coli, $0.1 \mathrm{~mL}$ of $10^{-8}$ were evenly spreaded on Petri plates and sterile filter paper discs impregnated with bioremediated, untreated dye solution and sterile distilled water were kept on the seeded bacterial cells at equidistance and pressed lightly and kept at $30{ }^{\circ} \mathrm{C}$ for $48 \mathrm{~h}$, observation for zone of inhibition was observed, if any (Kumar, 2011).

\section{Results}

Out of 61 fungal isolates, two fungal isolates were selected after comprehensive screening of the textile dyes biodegradation for further studies.

In tube overlay method, highest decolorization was observed in Malachite green and Nigrocin (92.85 and 93.33\% respectively), followed by Basic fuchsin (90.05\%) by $A$. niger. The mixture of dye decolorization was $10.4 \%$. In case of $P$. chrysosporium highest decolorization was observed in Maclachite green $71.42 \%$, followed by Basic fuchsin $(70 \%)$ and least was Nigrocin $(8.33 \%)$, while the mixture decolorization was $9.6 \%$ (Figure 1).

Dye decolorization in liquid medium exhibited different tendency as that of tube overlay method. In this method highest decolorization by $A$. niger was observed in Basic fuchsin $(81.85 \%)$, followed by Nigrocin $(77.47 \%)$, Malachite green $(72.77 \%)$ and least by dye mixture $(33.08 \%)$ under shaking conditions. While, under static conditions, highest decolorization was observed in Basic fuchsin (79.77\%), followed by Nigrocin (58.78\%) and Malachite green (50.37\%), least by dye mixture (24.38\%) (Figure 2).

Similarly, dye decolorization in liquid medium by $P$. chrysosporium exhibited different tendency as that of tube overlay method. In this method highest decolorization was observed in Nigrosin (90.15\%), followed by Basic fuchsin $(89.8 \%)$, Malachite green $(83.25 \%)$ and least by dye mixture $(68.4 \%)$ under shaking conditions (Figure 3 ).

Under stationary conditions, highest decolorization was observed in Nigrosin (65.04\%), followed by Malachite green $(53.75 \%)$ and Basic fuchsin $(52.6 \%)$ least by dye mixture $(40.6 \%)$ (Figure 3).

Change in $\mathrm{pH}$ was also observed by $A$. niger and $P$. chrysosporium under shaking and stationary conditions. After inoculation, the $\mathrm{pH}$ of all the dye samples was increased to neutral or near neutral (Figures 4, 5).

Microbial bioassay study showed that untreated dye (control) inhibited the growth of $E$. coli on Pteriplates by forming a zone of inhibition, while the treated dye did not show any zone of inhibition (Figure 6). Moreover, seed germination examination also showed the effect of untreated and treated dyes on germination of seeds. It was found that germination percentage was higher upto $90 \%$ by treated dye, while the untreated (control) dye inhibited the germination of wheat seeds (Figure 7). Data of zone of clearnce and seed germination is not mentioned due to brevity.

\section{Discussion}

The use of these fungi, thus could offer a much cheaper and efficient alternative treatment of wastewaters contaminated heavily with textile dyes. However, even though qualita-tive assays using the tube overlay method are powerful tools in screening fungi for extracellular enzyme produc-tion, they are not conclusive in that a negative reaction is not an absolute confirmation of a species' inability to produce a particular enzyme (Abdel-Raheem and Shearer, 2002). Hence, the tube agar overlay method (Lo-

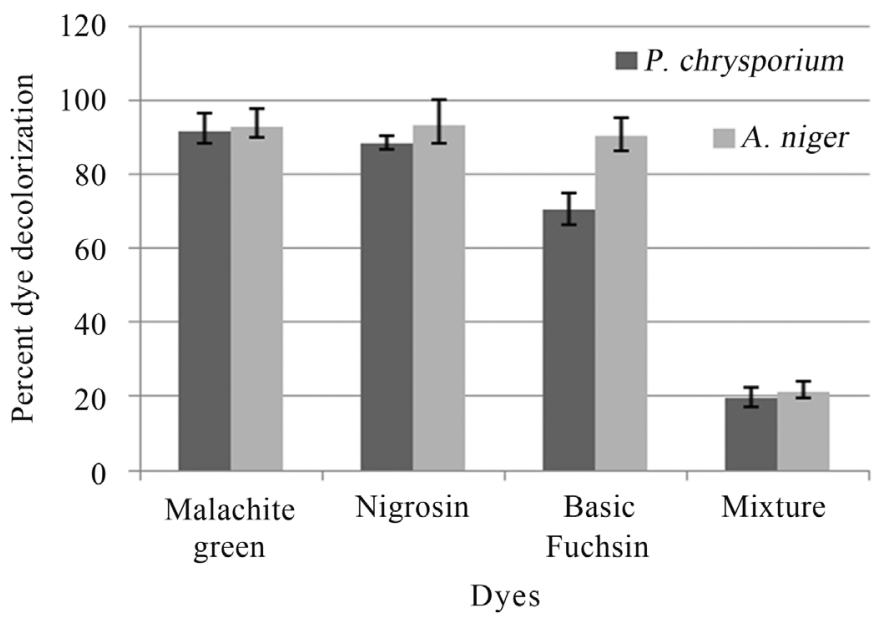

Figure 1 - Dye decolorizationby soil fungi in tube overlay method. 


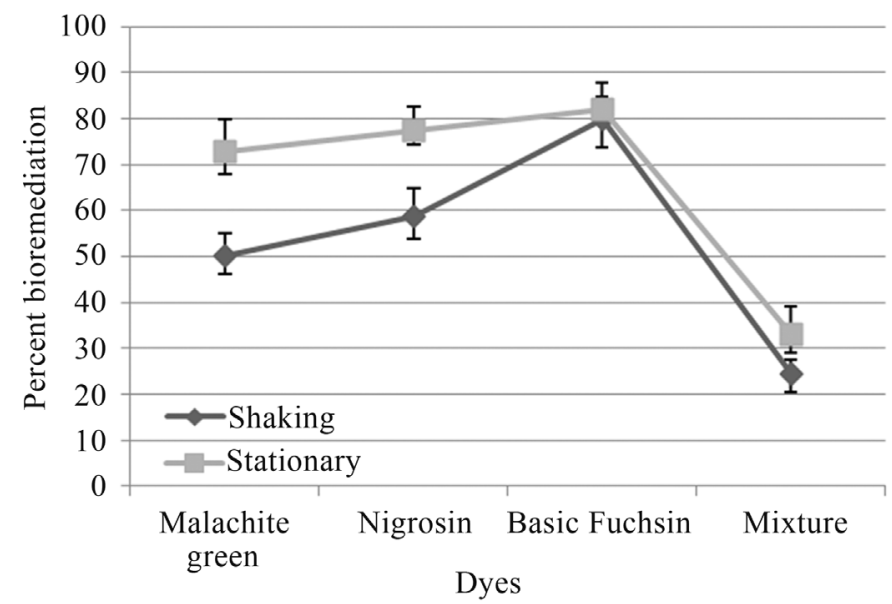

Figure 2 - Percent bioremediation of textile dyes by A. niger.

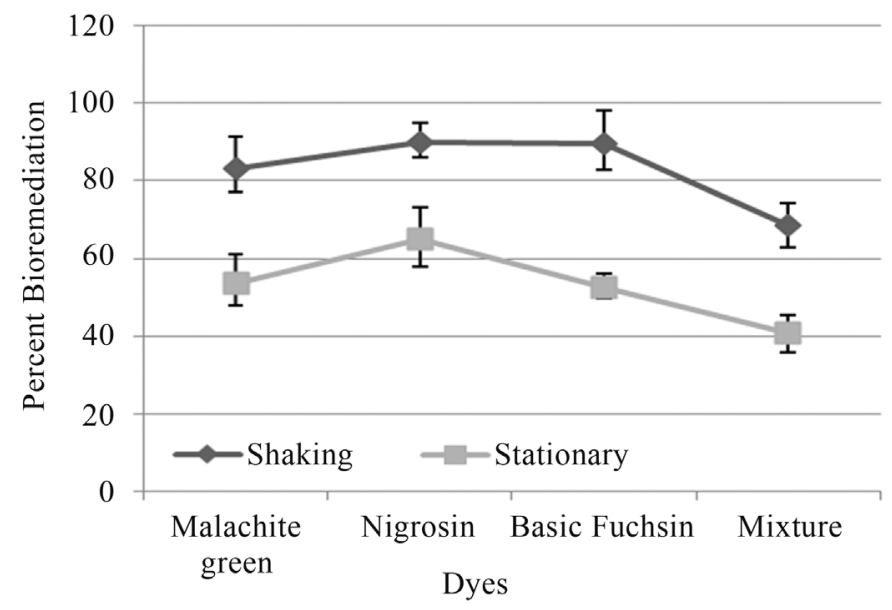

Figure 3 - Percent bioremediation of textile dyes by P. chrysosporium.

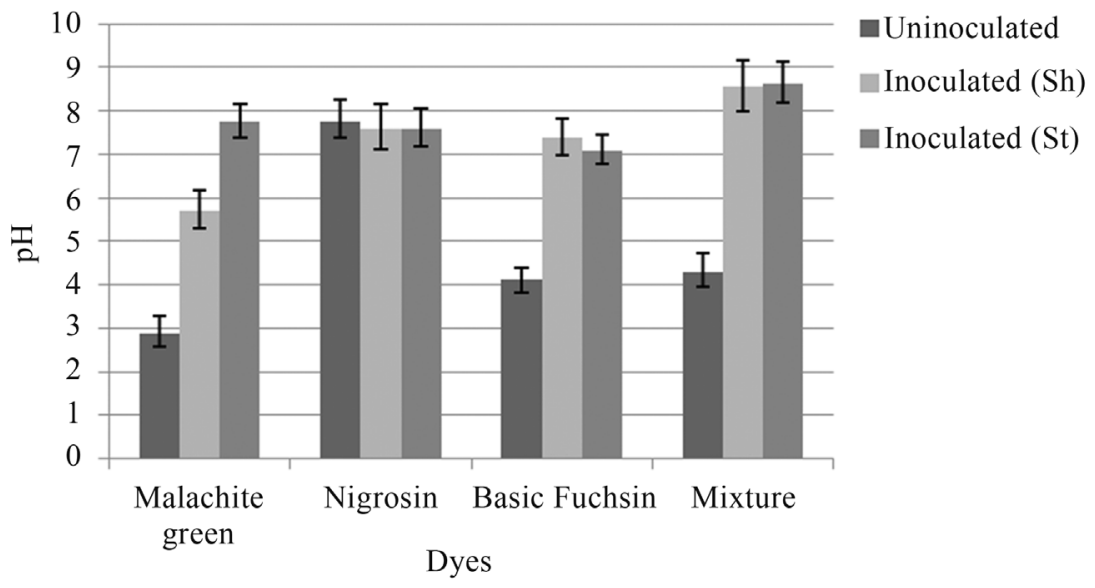

Figure 4 - Change in $\mathrm{pH}$ after inoculation with $A$. niger under shaking (Sh) and stationary (St) conditions.

pez et al., 2006) only provides an easier and quicker method to screen a large number of fungal isolates for further studying dye decolorization activity.
The removal of the dye color is vital in the potential ap-plication of effluent soil fungal organisms as bioremediation agents in wastewater treatment plants and in runoff waters. Thus, it is essential to test dye contaminated soil 


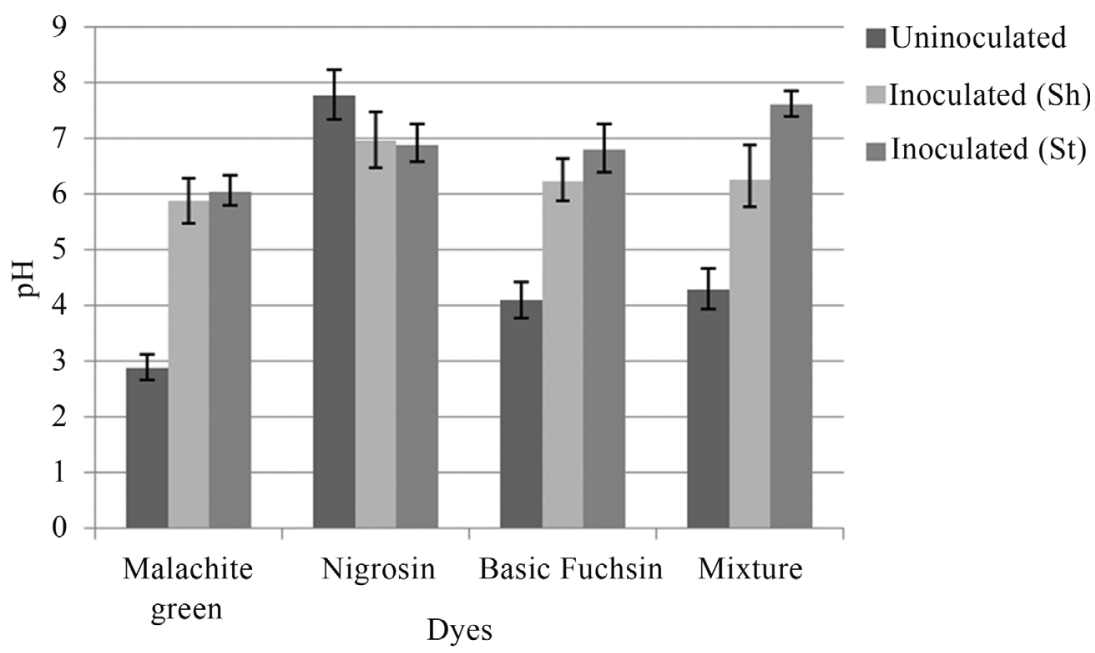

Figure 5 - Change in $\mathrm{pH}$ after inoculation with $P$. chrysosporium under shaking (Sh) and stationary (St) conditions.

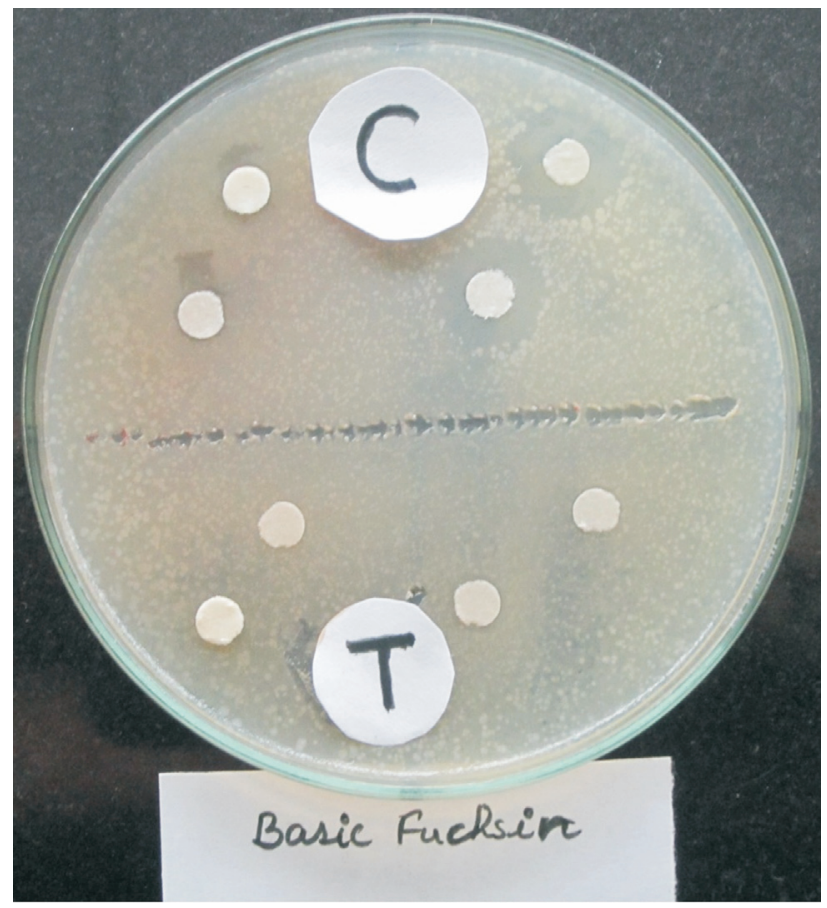

Figure 6 - Antimicrobial assay of Basic fuchsin $(\mathrm{C}=$ control dye; $\mathrm{T}=$ treated dye).

fungal strains for dye decolorization in liquid medium. Aspergillus niger and P. chrysosporium bioremediated Nigrosin, Basic fuchsin and Malachite green within 6 days up to $90 \%$. Kanmani et al. (2011) reported that Nigrosin was a substrate for the ligninolytic enzyme lignin peroxidase.

Microbes have developed enzyme systems for the decolourization of azo dyes, moreover, dye molecules display a high structural variety, and they are degraded by only few enzymes. These biocatalysts have one common mechanistic feature, they are all redox-active molecules and thus, exhibit relatively wide substrate specificities (Mester and Tien 2000). In the case of enzymatic remediation of azo dyes, azo reductases and laccases seem to be the most promising enzymes. These enzymes are multicopper phenol oxidases that decolourize azo dyes through a highly nonspecific free radical mechanism forming phenolic compounds, thereby avoiding the formation of toxic aromatic amines (Wong and Yu, 1999). Fungal systems appear to be most appropriate in the treatment of azo dyes (Ezeronye and Okerentugba, 1999). The capacity of fungi to reduce azo dyes is related to the formation of exo enzymes such as peroxidases and phenol oxidases. Peroxidases are hemoproteins that catalyze reactions in the presence of hydrogen peroxide (Duran et al., 2002). Laccase oxidizes the phenolic group of the phenolic azo dye, with the participation of one electron generating a phenoxy radical which is sequentially followed by oxidation to a carbonium ion. A nucleophilic attack by water on the phenolic ring carbon bearing the azo linkage to produce 3-diazenyl-benzenesulfonic acid (III) and 1, 2-naphthoquinone then takes place (Camarero et al., 2005).

Use of A. niger and P. crysosporium as dye biodegrader or decolorizer has been studied in this report and the efficient decolorization may be attributed to either through the ac-tion of extracellular enzymes such as laccase and/or biosorption by the fungal biomass. Laccase production by the soil fungal species have been studied, this test was performed to know, whether laccase enzyme plays any role in biodegradation of dyes. Furthermore, the soil fungal strains also showed promising decol-orization activities against tested dyes (Figures 3, 4). Ali et al. (2009) and Vasudev (2011) exhibited that Malachite green was readily degraded in liquid culture by A. flavus, A. solani and some white rot fungi within six days up to $96 \%$, as also shown in this study. Results of the dye biodegradation by soil fungi in this study using spectrophotometric analysis were even comparable with the percent dye decolorization exhibit-ed 


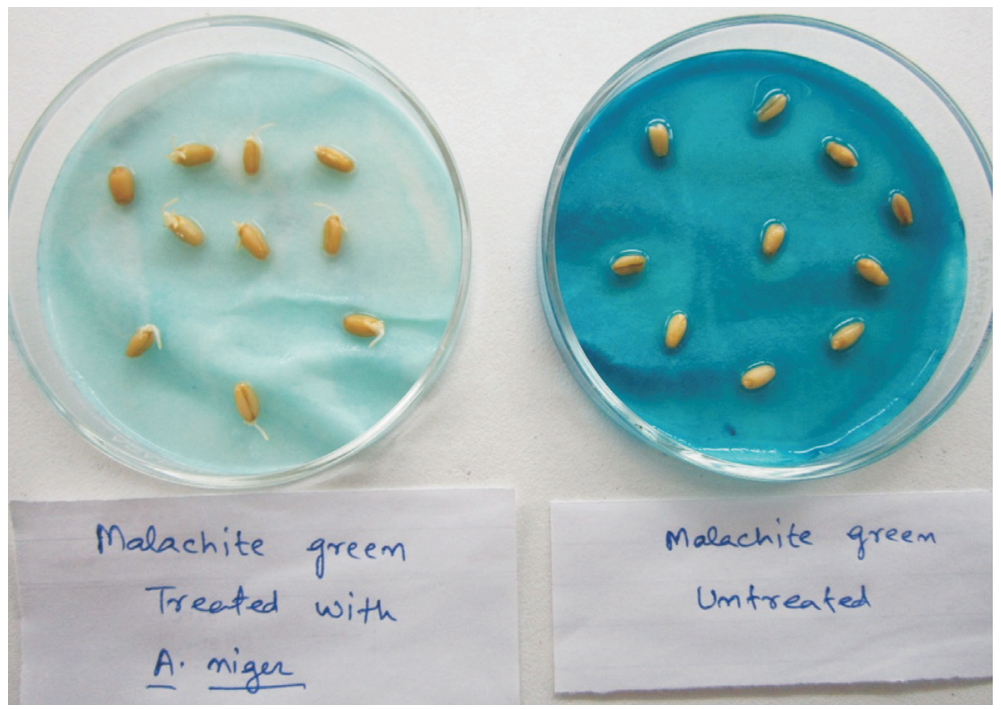

Figure 7 - Germination assay of wheat seeds by treated and untreated dye.

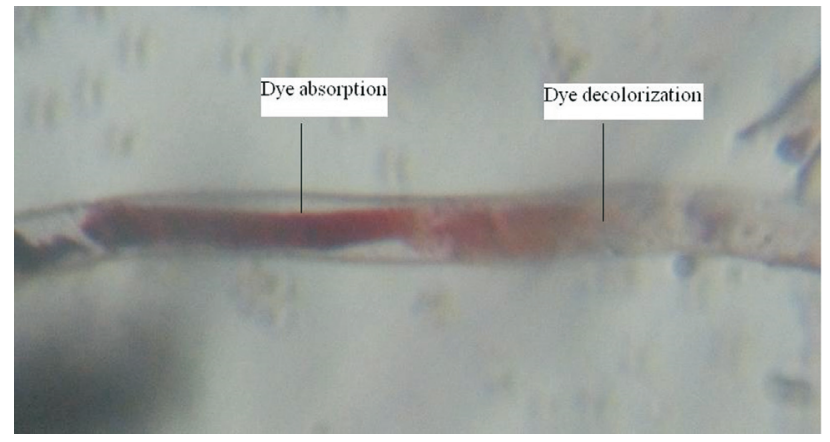

Figure 8 - Dye (Basic fuchsin) absorption and deolorization by A. niger hypha.

by the white-rot fungus Trametes versicolor and Pleurotus ostreatus (Yao et al., 2009), and even P. chrysosporium (Bumpus and Brock, 1988).

Soil fungi possess ligninolytic enzymes and play an im-portant role in the degradation of lignocellulose in soil ecosystems (Okino et al., 2000). These lignin-degrading enzymes are directly involved not only in the degradation of lignin in their natural lignocel-lulosic substrates but also in the degradation of various xenobiotic compounds, including dyes. Moreover, ligninolytic enzymes have been report-ed to oxidize many recalcitrant substances such as chlo-rophenols, polycyclic aromatic hydrocarbons (PAHs), organophosphorus compounds, and phenols (Wesenberg et al., 2003).

Additionally, it is not unusual for some species to demonstrate both enzyme-mediated degradation and biosorption in the decolorization of textile dyes (Park et al., 2007; Shahid et al., 2013). It is thus feasible that in addition to the production of extracellular enzymes, the ability of the dye effluent soil fungi to decolorize synthetic dyes is coupled also with their biosorption abilities (Kaushik and Ma- lik, 2009). We have also observed dye absorption by the test fungal mycelium under light microscope (1500 x) (Figure 8). This may account for the more efficient textile dye biodegradation by the soil fungal strains (Kirby et al., 2000) (Figures1-4). It is therefore, possible that the ability of dye effluent soil-derived fungi to degrade malachite green, Nigrosin and Basic fuchsin as revealed in this study can be largely attributed to the lignin-degrading enzyme system of the organism. In addition to extracellular enzymes, it is also likely that dye decolorization activity of these fungi could also be attributed to the ability of their mycelia to adsorb/absorb the dye. Bioremediation rate of dyes was higher with individual dyes as compared to dye mixture, which could be due the reason that a mixture of dyes forms different complex structures which become resistant for biodegradation.

Biosorption of dyes occur essentially either through complexation, adsorption by physical forces, precipitation, entrapment in inner spaces of fungal mycelium, ion exchange due to surface ionization, and by formation of hydrogen bonds (Yeddou-Mezenner, 2010). Due to an increased cell-to-surface ratio, fungi have a greater physical contact with the environment. Thus, some fungi have demonstrated better dye adsorption potential exceeding that of activated charcoal (Fu and Viraraghavan, 2002).

Detoxification of all the dyes was finally confirmed by the wheat seed germination and bacterial growth bioassay. The untreated dyes inhibited the wheat seeds germination after four days of incubation, while the seed germination was observed after $48 \mathrm{~h}$ in treated dyes treatments. Similarly, filter paper discs impregnated with untreated dye solution exhibited zone of inhibition of microbial growth, while the discs impregnated with treated dyes showed no zone of inhibition. The results of this study suggest that po- 
tentially competent fungal strains can be efficiently used for detoxification and bioremediation of harmful dyes.

\section{Conclusions}

The decolorization of dyes was studied under stationary and shaking conditions; encouraging results were obtained after 3 days, but maximum decolorization of all the dyes were obtained after 6 days. In this study we have observed higher decolorization under shaking conditions by $P$. chrysosporium and A. niger, which could be due to better oxygenation of the fungus and regular contact of secreted enzymes with dye molecules to decolorize it, moreover agitation also helps the fungus to grow better. Disappearance of dye color may be due to biodegradation of chromophore in dye molecule because of extracelluar enzyme production by fungi along with absorption and adsorption. Due to the environmental friendly techniques it utilizes, bioremediation has been characterized as a soft technology. Its cost-effectiveness and the little disturbance in the environment render this technology a very attractive and alternative method of choice. The identification and research of new fungal strains with the aid of molecular techniques will further improve practical applications of fungi and it is anticipated that fungal remediation will be soon a reliable and competitive dye remediation technology.

\section{Acknowledgments}

The authors are grateful to the Management, College of Applied Education \& Health Sciences, Meerut, India for providing research facilities to carry out this work.

\section{References}

Abdel-Raheem A, Shearer CA (2002) Extracellular enzyme production by freshwater ascomycetes. Fungal Diversity 11:119.

Ali H, Ahmed W, Haq T (2009) Decolorization and degradation of malachite green by Aspergillus flavus and Alternaria solani. African J Biotechnol 8(8):1574-1576.

Azbar N, Yonar T, Kestioglu K (2004) Comparison of various advanced oxidation processes and chemicaltreatment methods for COD and color removal from a polyester and acetate fibre dyeing effluent. Chemosphere 55:35-43.

Bumpus JA, Brock BJ (1988) Biodegradation of crystal violet by the white rot fungus Phanerochaete chrysosporium. Applied Environ Microbiol 54 (5):1143-1150.

Camarero S, Ibarra D, Martínez MJ, Angel, TM (2005) Ligninderived compounds as efficient laccase mediators for decolourization of different types of recalcitrant dyes. Appl Environ Microbiol 71(4):1775-1784.

Camarero S, Ibarra D, Martínez MJ, Angel, TM 2005. LigninDerived Compounds as Efficient Laccase Mediators for Decolourization of Different Types of Recalcitrant Dyes. Applied Environmental Microbiology 71(4):1775-1784.

Campos R, Kandelbauer A, Robra KH, Artur CP, Gubitz GM (2001) Indigo degradation with purified laccases from
Trametes hirsuta and Sclerotim rolfsii. J Biotechnology 8:131-139.

Casieri L, Varese GC, Anastasi A, Prigione V, Svobodova K, Marchisio VF, Novotny C (2008) Decolorization and detixication of reactive industrial dyes by immobilized fungi Tramets pubescens and Pleurotus ostreatus. Folia Microbiol 53(1):44-52.

Chung KT, Stevens SE, Cerniglia CE (1992) The reduction of azo dyes by the intestinal microflora. Critical Rev Microbiol 18:175-190.

Crini G (2006) Non-conventional low-cost adsorbents for dye removal: a review. Bioresource Technol 97(9):1061-85.

Dhanjal NIK, Mittu B, Chauhan A, Gupta S (2013) Biodegradation of textile dyes using fungal isolates. J Env Sci Technol 6(2):99-105.

Duran N, Rosa MA, D’Annibale A, Gianfreda L (2002) Applications of laccases and tyrosinases (phenoloxidases) immobilized on different supports: a review. Enzyme. Microbial Technol 31:907-931.

Eichlerova I, Homolka L, Nerud F (2006) Synthetic decolorization capacity of white-rot fungus Dichomitus sequalens. Bioresource Technol 97:2153-2159.

Elisangela F, Andrea Z, Fabio DG, Cristiano RM, Regina DL, Artur CP (2009) Biodegradation of textile azo dyes by a facultative Staphylococcus arlettae strain VN-11 using a sequential microaerophilic/aerobic process. Int Biodeterio Biodegrad 63:280-288.

Ezeronye O U, Okerentugba PO (1999) Performance and efficiency of a yeast biofilter for the treatment of a Nigerian fertilizer plant effluent. World. J Microbiol Biotechnol 15:515-516

Ferrero F (2007) Dye removal by low cost adsorbents: Hazelnut shells in comparison with wood sawdust. J Hazardous Mat 142:144-152.

Fu Y, Viraraghavan T (2002) Removal of Congo red from an aqueous solution by fungus Aspergillus niger. Advance Environ Res 7:239-247.

Galindo C, Kalt T (1999) UV/H2O oxidation of azo dyes in aqueous media: evidence of a structure - degradability relationship. Dyes Pigments 42:199-207.

Hassan MM, Alam MZ, Anwar MN (2013) Biodegradation of textile azo dyes by bacteria isolated from dyeing industry effluent. Int Res J Biol Sci 2(8):27-31.

Joshi B, Kabariya K, Nakrani S, Khan A, Parabia FM, Doshi HV, Thakur MC (2013) Biodegradation of turquoise blue dye by Bacillus megaterium isolated from industrial effluent. American J Environ Protec 1(2):41-46.

Kanmani P, Kumar SR, Yuvraj N, Parri KA, Pethikumar V, Arul V (2011) Microbial decolorization of synthetic dyes and reactive dyes of industrial effeuents by using novel fungaus Asprtgillus proliferans. Water Env Res 83(11):2099-2106.

Kaushik P, Malik A (2009) Fungal dye decolorization: recent advances and future potential. Environ Int 35:127-141.

Khaled E, Hassan G, Khider M, Mandour R (2010) Safe biodegradation of textile azo dyes by newly isolated lactic acid bacteria and detection of plasmids associated with degradation. J Biored Biodegrd 1(3):1-6.

Kirby N, Marchant R, McMullan G (2000) Decolorization of synthetic textile dyes by Phlebia tremellosa. FEMS. Microbiol Lett 188(1):93-96. 
Leebana VJ, Santhanum H, Geetha K, Raj SA (2012) Biodegrdation of direct golden yellow, a textile dye by Pseudomonas putida. Desalin Water Treat 39:1-9.

Lopez MZ, Guisado G, Garcia-Vargas MC, Estrella Suarez F, Moreno J (2006) Decolorization of industrial dyes by lignolytic microorganisms isolated from composting environment. Enzyme Microbial Technol 40:42-45.

Machado KMG, Luciana CA, Compart LCA, Morais RO, Luiz H, Rosa LH, Santos MH (2006) Biodegradation of reactive textile dyes by Basidiomycetous fungi from Brazilian ecosystems. Brazilian J Microbiol 37:481-487.

Mester T, Tien M (2000) Oxidative mechanism of ligninolytic enzymes involved in the degradation of environmental pollutants. Int Biodeter Biodegrad 46:51-59.

Okino LK, Machado KMG, Fabris C, Bononi VLR (2000) Ligninolytic activity of tropical rainforest basidiomycetes. World J Microbiol Biotechnol 16:889-893.

Park C, Lee M, Lee B, Kim SW, Chase HA, Lee J, Kim S (2007) Biodegradation and biosorption for decolorization of synthetic dyes by Funalia trogii. Biochem Eng J 36:59-65.

Rajamohan N, Karthikeyan C (2006) Kinetic studies of dye effluent degradation by Pseudomonas stutzeri. Retrieved from http://www.eco-web.com/edi/index.htm on 20 May 2011.

Ramalingam S, Saraswathy N, Shanmugapriya S, Shakthipriyadarshani S, Sadasivam S, Sanmugaprakash M (2010) Decolorization of textile dyes by Aspergillus tamari, mixed fungal culture and Peniceillium purpurogenum. J Scien Ind Res 69:151-153.

Robinson T, McMullan G, Marchant R, Nigam P (2001) Remediation of dyes in Textile effluent: A critical review on current treatment technologies with a proposed alternative. Bioresource Technol 77:247-255.

Shahid A, Singh J, Bisht S, Teotia P, Kumar V (2013) Biodegradation of textile dyes by fungi isolated from North Indian field soil. Env. Asia 6(2):51-57.

Siddique M, Mahmmod A, Sheikh M, Gafoor A, Khaliq S, Bukhai M, Yousaf K, Rehman K, Andleeb S, Naeem MM (2012) A study on the biodegradation of some reactive textile dyes by white rot fungus (Pleurotus ostreatus). World Appl Sci J 18 (2):181-185.

Suryavathi V, Sharma S, Sharma S, Saxena P, Pandey S, Grover R, Kumar S, Sharma KP (2005) Acute toxicity of textile dye wastewaters (untreated and treated) of Sanganer on male reproductive systems of albino rats and mice. Reproductive Technol 19:547-556.

Tisma M, Komar M, Rajic M, Pavlovic H, Zelic B (2012) Decolorization of dyes by Aspergillus Ochraceus cultivated under solid state fermentation on sugar beet waste. Chem Eng Transac. 27:62-67.

Valmaseda M, Martinez MJ, Marinez AT (1991) Kinetics of wheat straw solid- state fermentation with Trametes versicolor and Pleurotus ostreatus- lignin and polysaccharide alteration of related enzymatic activities. Appl Microbiol Biotechnol 35:817-823.

Vasudev, K (2011) Decolorization of triphenylmethane dyes by six white rot fungi isolated from nature. J Bioremed Biodegrad 2(5):61-66.

Wesenberg D, Kyriakides I, Agathos SN (2003) White-rot fungi and their enzymes for the treatment of industrial dye effluents. Biotechnol Adv 22:161-187.

Wong Y, Yu J (1999) Laccase-catalyzed decolourization of synthetic dyes. Water Res 33:3512-3520.

Yang XQ, Zhao XX, Liu CY, Zheng Y, Qian SJ (2009) Decolorization of azo, triphenylmethane and anthraquinone dyes by a newly isolated Trametes sp. SQ01 and its laccase. Process Biochem 4:1185-1189.

Yao MLC, Villanueva JDH, Tumana MLS, Caalimg JG, Bungihan ME, Dela Cruz TEE (2009) Antimicrobial activities of marine fungi isolated from seawater and marine sediments. Acta Manilana 57:19-28.

Yeddou-Mezenner N (2010) Kinetics and mechanism of dye biosorption onto an untreated antibiotic waste. Desalination 262:251-259.

Zollinger H (1991) Azo Dyes and Pigments. Colour Chemistry-Synthesis, Properties and Applications of Organic Dyes and Pigments. VCH, New York, p. 92-100.

All the content of the journal, except where otherwise noted, is licensed under a Creative Commons License CC BY-NC. 